\title{
Influence of Particle Orientation on the Performance of Geogrid Reinforced Ballast
}

\author{
Jian-bin Zhao $\mathbb{D},{ }^{1,2}$ Jie Li $\mathbb{D},{ }^{1}$ Xiao-hong Bai $\mathbb{i}$, ${ }^{1}$ Chen-xi Miao $\mathbb{D},{ }^{1,2}$ and Jun Zhang $\mathbb{D}^{2}$ \\ ${ }^{1}$ Taiyuan University of Technology, Taiyuan 030000, China \\ ${ }^{2}$ Shanxi Transportation Technology ReD Co. Ltd., Taiyuan 030000, China \\ Correspondence should be addressed to Xiao-hong Bai; bxhong@tyut.edu.cn
}

Received 24 June 2020; Revised 30 November 2020; Accepted 14 December 2020; Published 28 December 2020

Academic Editor: Giorgio Pia

Copyright ( 92020 Jian-bin Zhao et al. This is an open access article distributed under the Creative Commons Attribution License, which permits unrestricted use, distribution, and reproduction in any medium, provided the original work is properly cited.

To explore the initial orientation effect of ballast assembly on the reinforcement performance of the geogrid reinforced ballast, particles with random orientation and five prescribed rotational orientations were developed through particle flow code (PFC3D). The evolution laws of the pullout force and the principal directions of the normal contact force were systematically compared and analyzed. Furthermore, the mechanical responses such as pullout force, distribution of axial force, displacement vectors, force chain, and mesoscopic fabric were discussed. According to the displacement vectors of the ballast particles, the average thickness of the stable shear band is determined. The inherent relationships among the force chain, the rotational angle of the normal contact force, and the mesoscopic fabric parameters are revealed. The results show that the pullout force of specimens with the initial orientation of $45^{\circ}$ increases monotonously during the pullout process, and the peak value of pullout force appears at the end of the test. The mesostructural analysis also confirms that the evolution of the principal direction of contact normal force is relatively steady during the pullout process, indicating that the specimen with $45^{\circ}$ orientation possesses higher systematic stability and ductility. Moreover, the optimum interval from $56.68^{\circ}$ to $57.30^{\circ}$ is observed to remain in a self-adapting state for ballast assembly.

\section{Introduction}

Compared with the considerable compressive strength, the tensile strength of soil is nearly negligible, especially for coarse aggregates. Geogrid, as a manner of reinforcing material, increases stability, structural strength, and bearing capacity of the soil [1-3]. Gradually, geosynthetics reinforced technology has been used in slopes, railways, and dykes [4-6]. However, the load transfer mechanism of geogrid-soil system has not been revealed $[7,8]$. Continuous attempts and improvements have been made by scholars, including the influence of normal stresses, pullout speed, geogrid size, geogrid shape, and particle size on the reinforced soil [9-11]. Laboratory pullout tests can reflect the evolution laws of reinforced structure splendidly but fail to clearly reveal the distribution mechanism of geogrid-soil interface force and the transfer mode of axial force of geogrid [12-14]. Moreover, traditional laboratory pullout tests can merely monitor macroscopic mechanical response. One inherent defect of laboratory tests is that it is difficult to analyze and study microscopic parameter evolution, such as local void ratio and coordination. Therefore, the state of the whole pullout tests system cannot be accurately reflected $[10,15]$.

To bridge the gap in laboratory pullout tests, the macroscopic and microscopic characteristics of the geogrid-soil interface have been studied by plenty of scholars in numerical simulation. For instance, Hussein et al. [16] accurately established the geogrid model using the finite element model and found that the numerical model could obtain the real response of the geogrid under unconstrained and constrained conditions. Mohammed et al. [17] used finite element method to analyze the stone column, predicted the deformation of soil, and studied the mechanical properties of standard and nested floating stone columns under different conditions by using parametric method. Sun et al. [18] 
analyzed the stability of reinforced slopes by strength reduction method and found the relationship between strain of geogrid and safety factor. The attempts mentioned above were based on the assumption of a continuous medium but ignored the properties of rotating, sliding, and displacement of granular materials and were difficult to reveal the mesoanisotropic evolution of the reinforced soil interface.

The discrete element method (DEM) has been extensively used in investigating the overall performance of the railway ballast, and due to the discrete nature, the particle motion and the load transfer through particle contact that intrinsically induce the evolution of macroscopic strength can be explicitly recognized. Huang et al. [19] built a dynamic track model to assess the railway performance under particular consideration of freight and train speed, and a specific suggestion was proposed that mixed freight and high speed traffic is the worst combination due to the higher settlement rate. Suhr et al. [20] calibrated two sets of parameters for two types of ballast mineral (calcite and kieselkalk) using the Conical Damage Model (CDM) contact law, and compared with the simplified Hertz-Mindlin contact law, the newly proposed CDM model is more sophisticated since it can better reproduce the shearing and compression behavior of multiple minerals of railway ballast. Meanwhile, Vizcarra et al. [21] studied the deformation behavior of ballast considering the effect of particle size distribution, and meaningful features such as the coordination number captured in DEM show that the micromechanical responses are sensitive to the particle gradation. Overall, DEM has been demonstrated to be robust in reproducing the mechanical response and mesoscopic characteristics of granular materials [22-27]. Current studies have confirmed that the interaction between the reinforcement and the soil is very complex, and the joint strength, aperture shape, and size of the reinforcement significantly affect the stability of the reinforced soil, but the spatial orientation of particle assembly is rarely involved. This article aims to characterize the pullout behaviors of a triaxial geogrid embedded in ballast aggregates with different initial particle orientations, which is expected to play a significant role in the stability of geogrid reinforced system. Besides the random orientation used in pullout tests, the other five particles orientations (i.e., the specimens with $0^{\circ}$, $30^{\circ}, 45^{\circ}, 60^{\circ}$, and $90^{\circ}$ orientations) are also explored. Finally, the microfabric, displacement vectors, axial force of geogrid, segmental strain, and force chain are analyzed, and the evolution law of pullout force and the principal directions of normal contact force anisotropy are compared with different initial orientations, which provides a certain reference for improving the performance of geogrid reinforced ballast from the perspective of particle arrangement.

\section{DEM Modeling}

2.1. Pullout Test Steps. Figure 1(a) shows the DEM modeling of pullout test, and it is noted that, for observation purposes, coordinate system and pullout direction have been given for easy realization of testing settings. And Figure 1(b) presents the relative position between the geogrid and the box boundary. A geogrid embedded ballast specimen included 2 segments, namely, a front segment of $130 \mathrm{~mm}$ with the transverse ribs removed and a rear segment of $120 \mathrm{~mm}$ with intact aperture. The testing box with the initial sizes of $300 \mathrm{~mm} \times 300 \mathrm{~mm} \times 400 \mathrm{~mm}(x \times y \times z)$ is composed of 11 rigid walls, and the pullout outlet with the height of $6 \mathrm{~mm}$ is reserved for the generation of geogrid. The linear contact model is adopted in the modeling walls, whose stiffness and strength are set to $10^{5} \mathrm{kN} / \mathrm{m}^{3}, 10^{5} \mathrm{kN} / \mathrm{m}^{3}$, respectively. It is noteworthy that the value of wall-particle friction coefficient is 0 to reduce wall-particle frictional energy. Numerical simulation procedures can be described as follows:

(1) A total number of 10776 spherical particles are generated and then spherical particles are replaced by triball particles with prescribed orientations.

(2) Add gravity filed $\left(g=9.8 \mathrm{~m} / \mathrm{s}^{2}\right)$ and cycle to balance, and the servo-control mechanism is introduced to maintain the stress state of the specimen.

(3) Generate the geogrid particles in the reserved room.

(4) Remove the reserved walls and allow the contact of the ballast and geogrid, and adjust the ballast assembly to the prescribed stresses, i.e., $20 \mathrm{kPa}, 30 \mathrm{kPa}$, $40 \mathrm{kPa}$, and $50 \mathrm{kPa}$.

(5) Clear the displacement and velocity information of all triball particles. The adoptive time step is identical for different working conditions, and it is guaranteed that the value of the time step is lower than the system default time step.

(6) Apply a constant velocity of $0.0375 \mathrm{~m} / \mathrm{s}$ to the clamp end of geogrid, and start pulling out along the longitudinal ribs. A total of $90 \mathrm{~mm}$ pullout displacement is conducted, and process data of interest is periodically recorded at an interval of $0.9 \mathrm{~mm}$.

2.2. Modeling of Ballast. The ballast assembly with the initial porosity of 0.45 is generated in the testing box. Considering the inherent defect of spherical particles in reproducing the rotation and fabric behavior of real ballast, triball particles with specific features below are developed in this study: (1) Each triball particle comprises three identical original sphere balls. (2) The pebble units overlap between each other, and the centers of the spheres are coplanar. (3) In the current algorithm, contacts among pebble units are ignored. In the process of particle transformation, the principles of volume and mass equivalence are strictly obeyed to ensure that the volume and mass are equivalent with the former spherical ones. A linear contact model is adopted to simulate the interaction among the transformed particles. To study mechanical effect of initial particle orientation on geogridsoil interface, the specimens with diverse initial orientation were established, the orientation was defined by the angle between the primary plane of the ballast and the yoz plane of the model, and the random orientation was also supplemented as a contrast; six orientation conditions are schematically given in Figures 2(a)-2(f). Ngo et al. [28] have successfully proposed the microscopic parameters regarding 


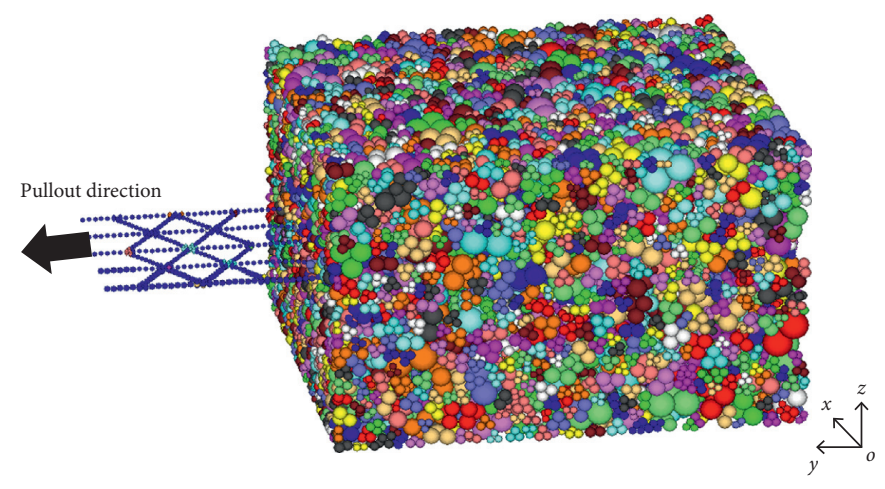

(a)

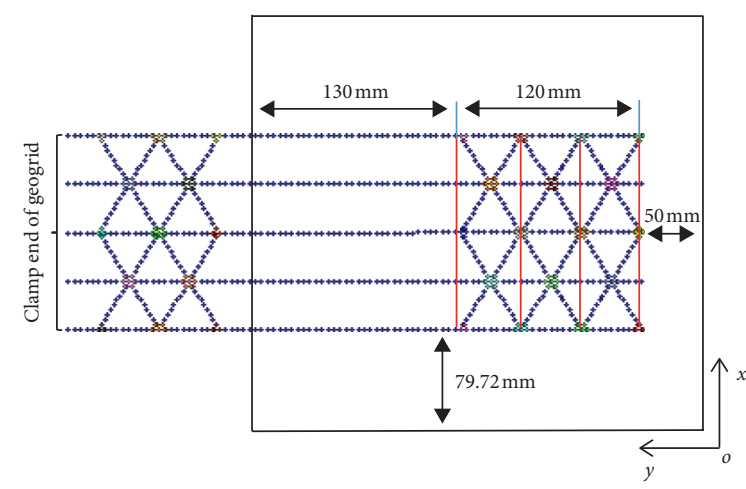

(b)

Figure 1: Schematic diagram of the test settings. (a) Numerical model for pullout tests. (b) Plane view of geogrid configuration.

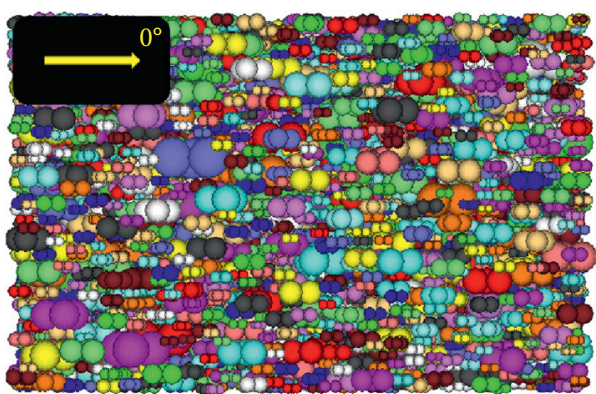

(a)

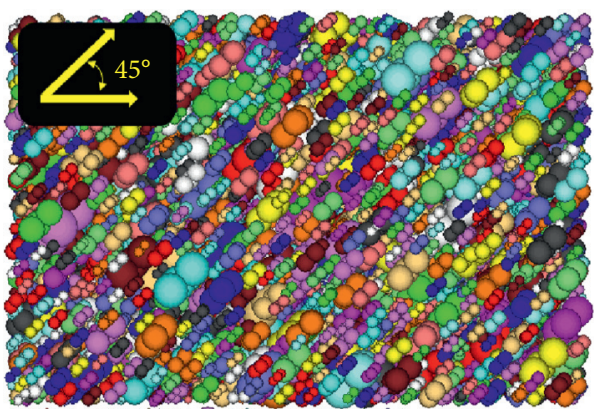

(c)

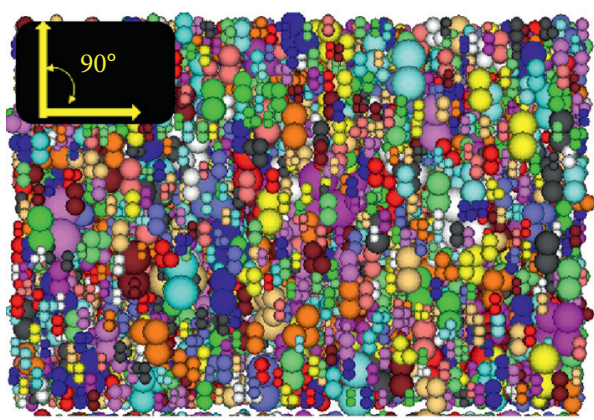

(e)

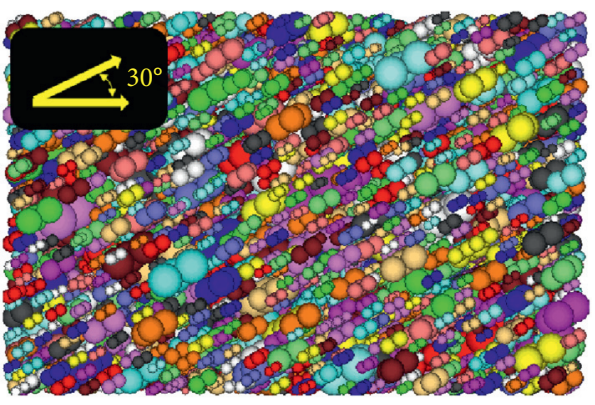

(b)

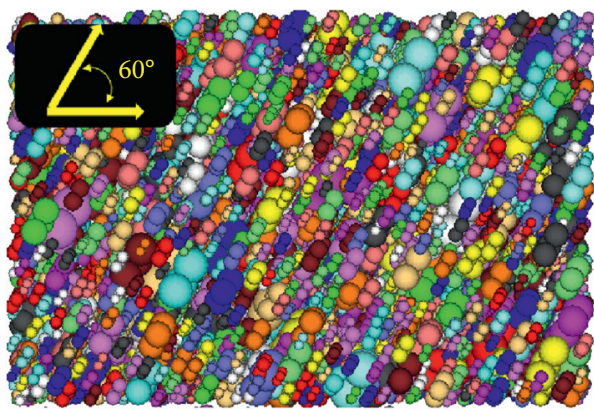

(d)

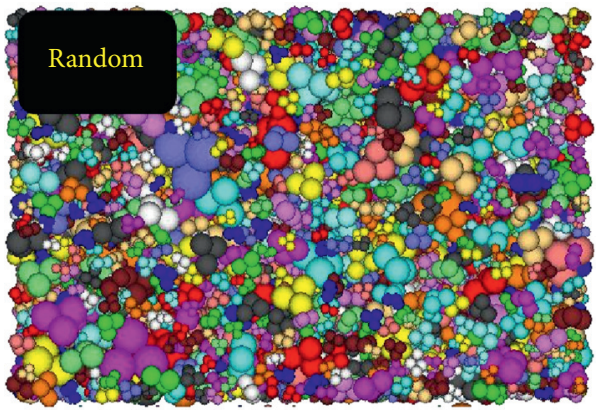

(f)

Figure 2: DEM specimens with different particle orientations. (a) $0^{\circ}$ orientation. (b) $30^{\circ}$ orientation. (c) $45^{\circ}$ orientation. (d) $60^{\circ}$ orientation. (e) $90^{\circ}$ orientation. (f) Random orientation. 
the ballast and geogrid, which was adopted in the current DEM modeling and listed in Table 1.

\subsection{Modeling of Geogrid with Triangular Aperture.} Parallel bond model is used to establish geogrid in the DEM simulation based on mechanical properties of the transmission of force and moment among adjacent entities. The size of a signal triangular aperture is $40 \mathrm{~mm} \times 40 \mathrm{~mm} \times 40 \mathrm{~mm}$, and ribs are composed of the diameter of $4 \mathrm{~mm}$ of spherical particles. The protrusive junction modeling is performed firstly by creating the host joints with a diameter of $4 \mathrm{~mm}$ and then adding the subordinate joints with a diameter of $3 \mathrm{~mm}$, and the upper and lower subordinate particles are tangent to the center of the host particle, as suggested by Miao et al. [27]. To prevent restriction of ballast assembly at pullout outlet during the test process, the transverse ribs within $130 \mathrm{~mm}$ near the pullout outlet are removed. The geogrid junctions and the projection on the $\mathrm{xoz}$ plane are shown in Figure 3, and microscopic parameters of geogrid are listed in Table 1.

\section{Pullout Behavior of Geogrid Embedded in Ballast Assembly}

The accuracy of the modeling has been verified from axial force distribution, pullout force, and the geogrid strain by Biabani et al. [26], and essential factors such as joints structure and microscopic parameters in the current study have also been testified by Miao et al. [27]. Compared with the previous models, the orientation of ballast is merely adjusted to accommodate the research objective, while other dimensional and mechanical parameters are referred from above previous studies [26-28]. Thus, modeling verification is no longer carried out in this article.

3.1. Pullout Force. To analyze the interface strength of reinforced ballast and the geogrid performance, the pullout tests of geogrid embedded in the specimen with $45^{\circ}$ ballast orientation are carried out under four different normal stresses. Figure 4 shows the DEM simulation of pullout forces against clamp end displacement, and it is observed that the pullout forces increase linearly and develop synchronously during the first $10 \mathrm{~mm}$ of displacement. Thereafter, the pullout forces increase at different rates, and a general observation is that higher normal stress gives rise to a steeper growth rate of pullout force. In other words, under the same pullout displacement, the peak pullout forces increase with the increase of normal stresses. The trend of pullout force is consistent with the findings reported by Tran et al. [29], Stahl et al. [30], Sugimoto et al. [31], and Suksiripattanapong et al. [32].

3.2. Axial Force along the Geogrid. Figure 5 presents the relationship between the distributions of axial forces and four typical clamp end displacements under the normal stress of $20 \mathrm{kPa}$. It can be observed from Figure 5(a) that the axial forces of longitudinal ribs are evenly distributed with negligible magnitudes under slight disturbance of the pullout load. As illustrated in Figures 5(b) and 5(c), the axial forces of longitudinal ribs develop further, and the mobilization of the last transverse rib can be recognized by comparing the end position in the coordinate system. On the whole, the axial forces decrease gradually from the clamp end to the free end of geogrid. The phenomenon is owing to the hypothesis that the frictional resistance of the reinforced interface is dominant compared with the interlocking effect of geogrid-ballast interface at the early stage. As the motivation of particle assembly accumulates with the proceeding of pullout test, the passive resistance of the transverse ribs is gradually activated, and the nonuniform development of axial forces is possibly caused by the complex spatial location distribution of ballast particles. The final state can be seen in Figure 5(d), the geogrid is gradually pulled out, and the axial forces decrease since the bearing structure of the particle system is partially degraded by the disturbance imported from the clamp end.

3.3. Displacement Vectors of Ballast. To further analyze the evolution process of mechanical response at the reinforced ballast interface, the disturbance of the ballast particles described by the displacement vectors under different pullout stages is shown in Figure 6. The direction and scale of particle movement are included in displacement vectors, and dense displacement vectors correspond to intensive particle motivation. The initial stage can be seen in Figure 6(a), in which the particles disturbance and the shear band around geogrid-ballast interface are relatively inconspicuous. With the development of the geogrid displacement (as shown in Figures 6(b) and 6(c)), the disturbance of the ballast particles becomes distinct, the thickness of the shear band increases further, and the displacement vectors grow gradually. As the final clamp end displacement approaches, the displacement vectors of ballast particles no longer increase with the development of geogrid displacement and show a relatively stable shear band, and the range of stable shear band is empirically determined within $40 \mathrm{~mm}$ of the reinforced soil interface. In short, the analysis of particle displacement vectors is beneficial for understanding the interaction of geogrid-ballast system.

3.4. Force Chain. Fabric anisotropy is analyzed to study the inherent changes that explain the development of strength of the geogrid-ballast interface. The well-established method is the Fourier approximation method proposed by Rothenburg and Rathurst [19]. The formula is as follows:

$$
f_{n}(\theta)=f_{0}\left[1+a_{n} \cos 2\left(\theta-\theta_{n}\right)\right],
$$

where $f_{n}, f_{0}, a_{n}$ and $\theta_{n}$ represent the distributions functions of contact normal force, the average value of contact normal force, the anisotropic coefficients of contact normal force, and the principal directions of contact normal force, respectively.

As shown in Figure 7, the polar distribution of contact normal forces in the region of interest (highlighted in 
TABle 1: Model parameters.

\begin{tabular}{lcc}
\hline Category & Ballast & Geogrid \\
\hline Particle density $\left(\mathrm{kg} / \mathrm{m}^{3}\right)$ & 2700 & 800 \\
Porosity & 0.45 & - \\
Contact normal stiffness $(\mathrm{kN} / \mathrm{m})$ & $0.52 \times 10^{5}$ & $1.77 \times 10^{4}$ \\
Contact normal stiffness $(\mathrm{kN} / \mathrm{m})$ & $0.52 \times 10^{5}$ & $0.88 \times 10^{4}$ \\
Coefficient of friction & 0.8 & 0.5 \\
Parallel bond normal stiffness, $k_{n p}\left(\mathrm{kN} / \mathrm{m}^{3}\right)$ & - & $5.68 \times 10^{8}$ \\
Parallel bond shear stiffness, $k_{s p}\left(\mathrm{kN} / \mathrm{m}^{3}\right)$ & - & $5.68 \times 10^{8}$ \\
Parallel bond normal strength, $s_{n p}\left(\mathrm{kN} / \mathrm{m}^{2}\right)$ & - & $4.56 \times 10^{5}$ \\
Parallel bond shear strength, $s_{s p}\left(\mathrm{kN} / \mathrm{m}^{2}\right)$ & - & $4.56 \times 10^{5}$ \\
Parallel bond radius multiplier & - & 0.5 \\
\hline
\end{tabular}

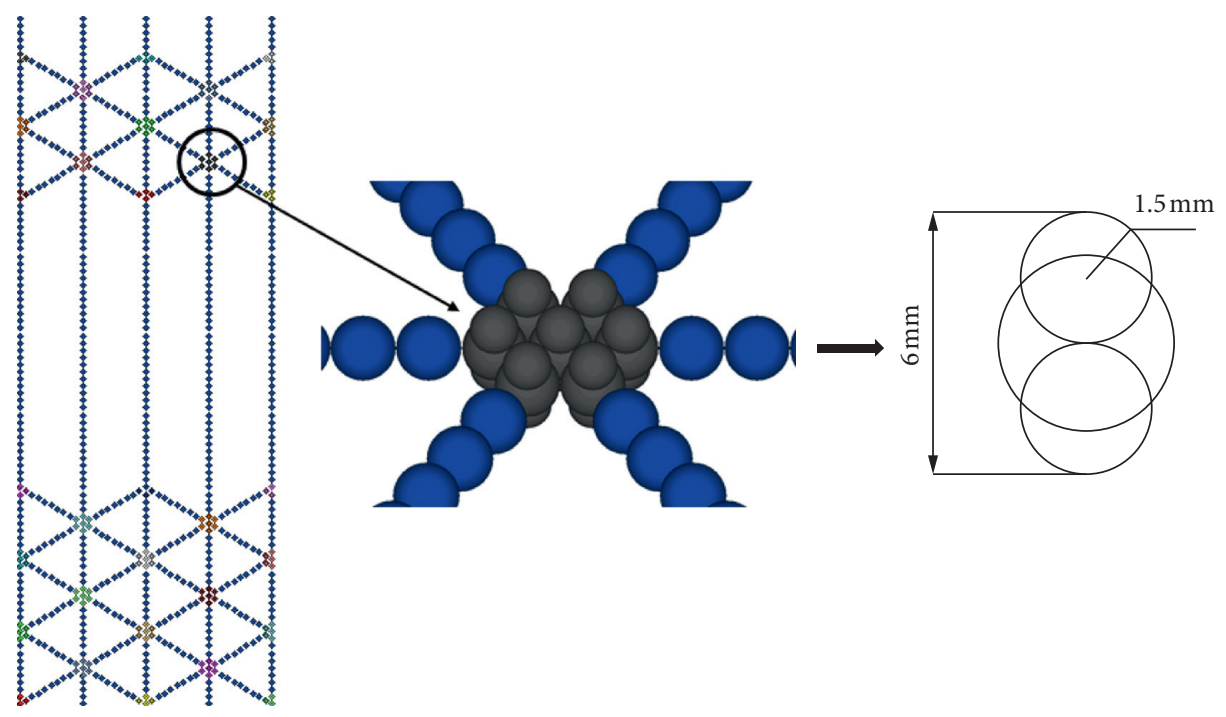

Figure 3: Model of geogrid and junctions.

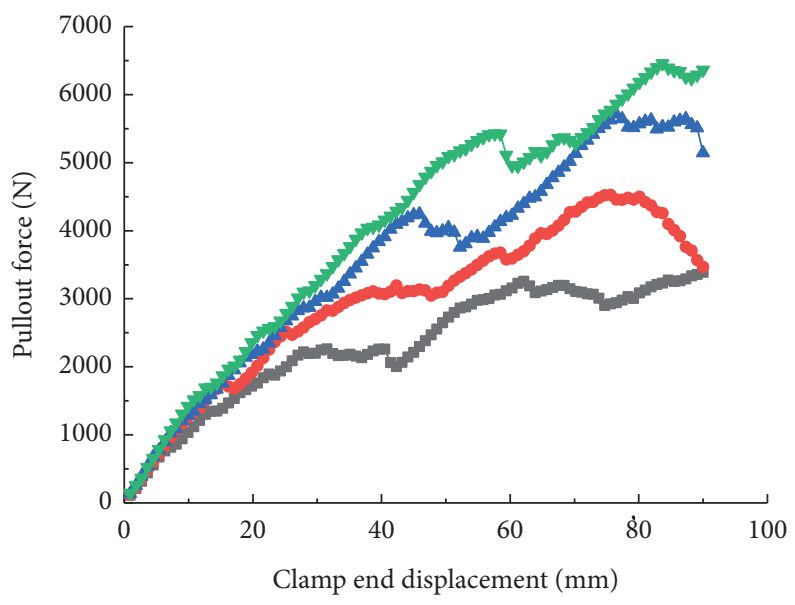

Normal stress

$\begin{array}{ll}-20 \mathrm{kPa} & \rightarrow 40 \mathrm{kPa} \\ \rightarrow 30 \mathrm{kPa} & \rightarrow 50 \mathrm{kPa}\end{array}$

Figure 4: Variation of pullout force versus clamp end displacement. 


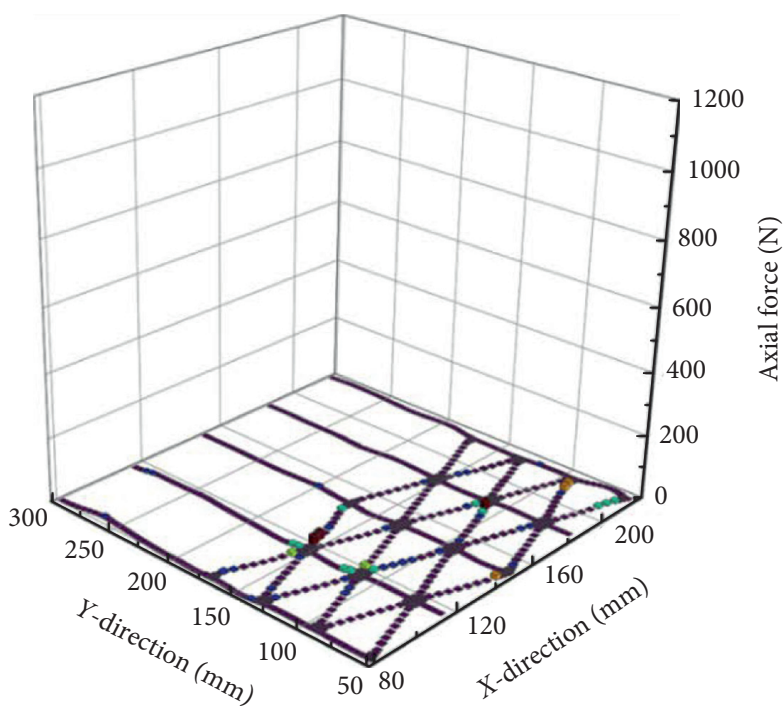

(a)

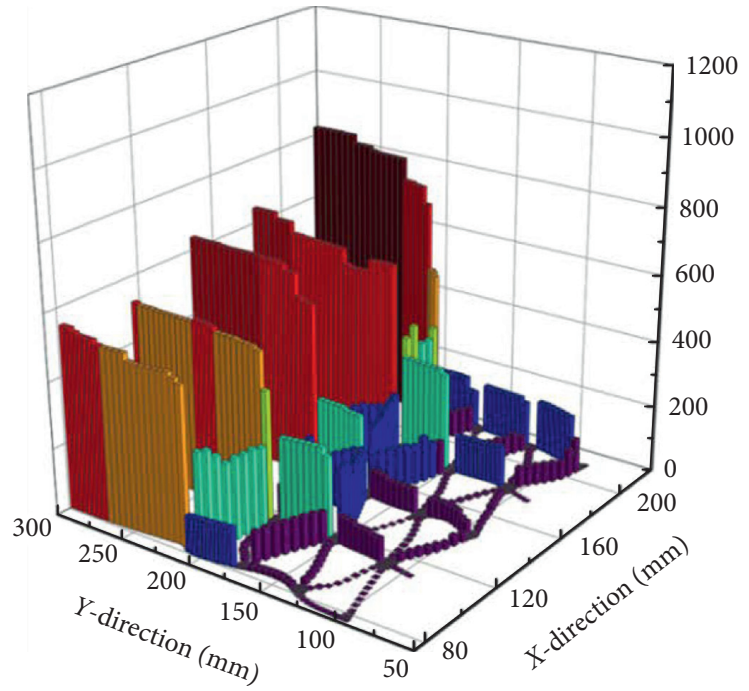

(c)

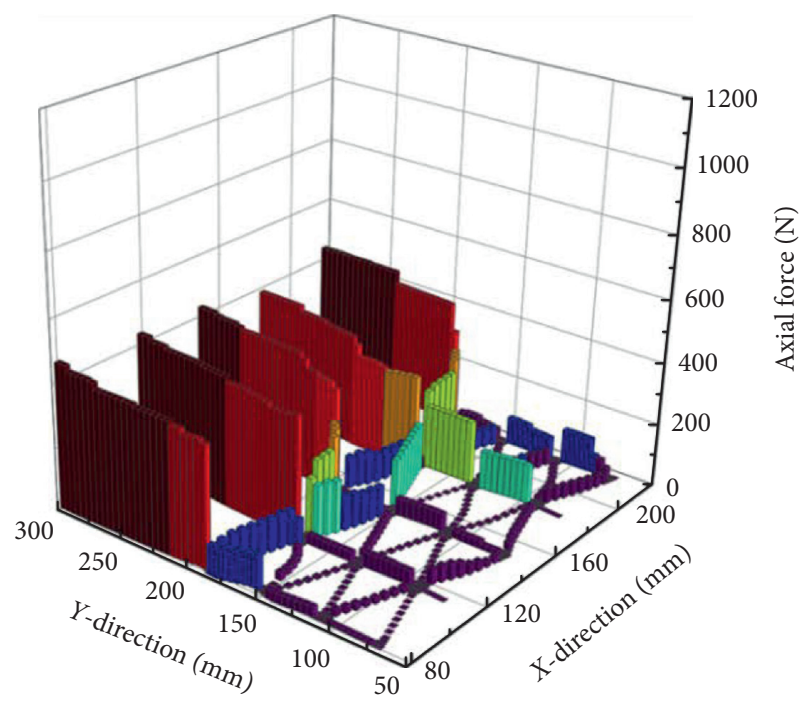

(b)

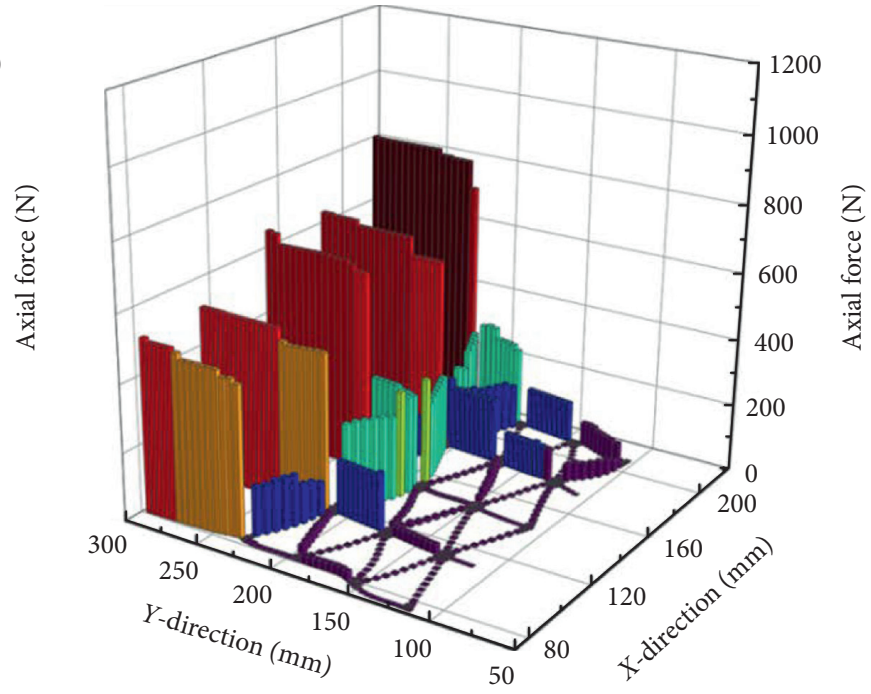

(d)

Figure 5: Axial forces for various clamp end displacements. (a) $\delta=36 \mathrm{~mm}$. (b) $\delta=36 \mathrm{~mm}$. (c) $\delta=63 \mathrm{~mm}$. (d) $\delta=81 \mathrm{~mm}$.

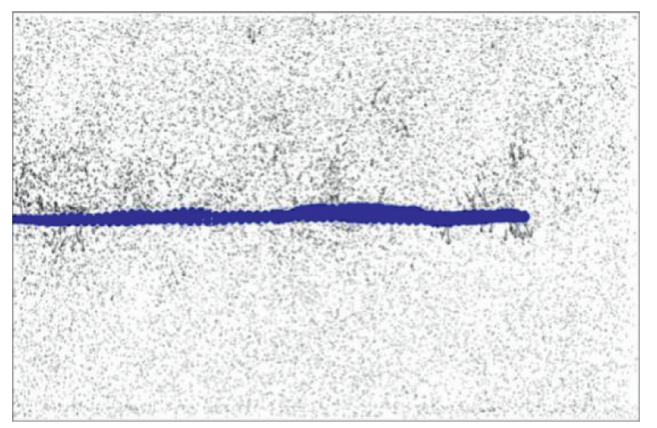

(a)

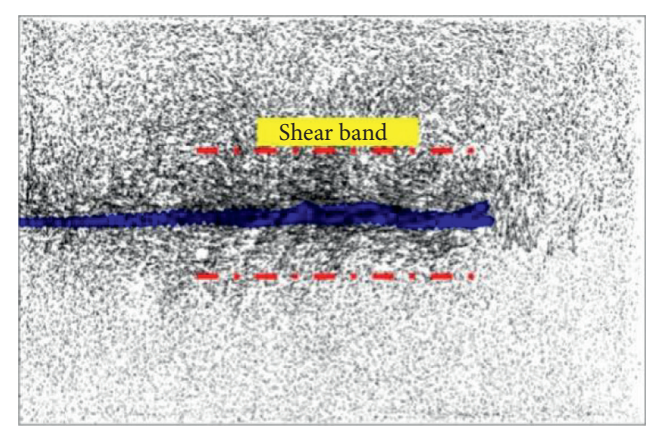

(b)

FIgUre 6: Continued. 


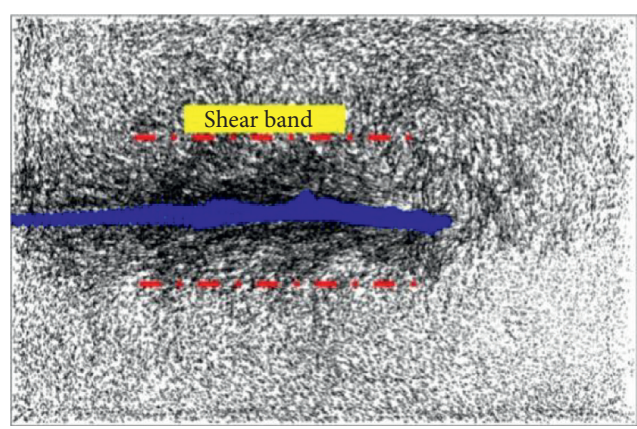

(c)

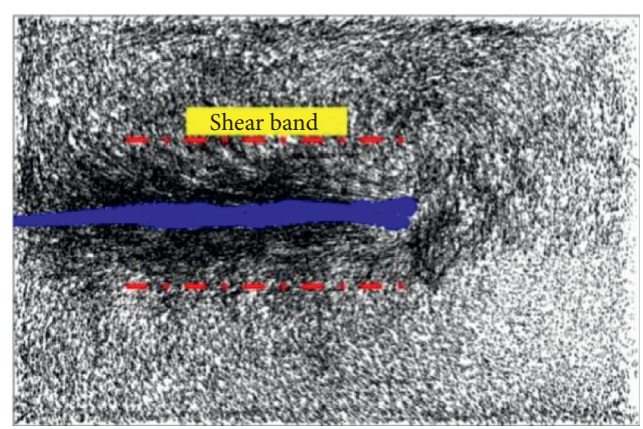

(d)

Figure 6: Displacement vectors for different clamp end displacements. (a) $\delta=9 \mathrm{~mm}$. (b) $\delta=36 \mathrm{~mm}$. (c) $\delta=63 \mathrm{~mm}$. (d) $\delta=81 \mathrm{~mm}$.

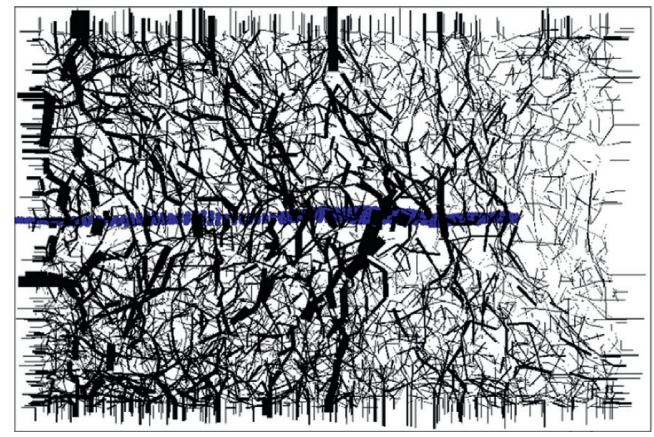

(a)
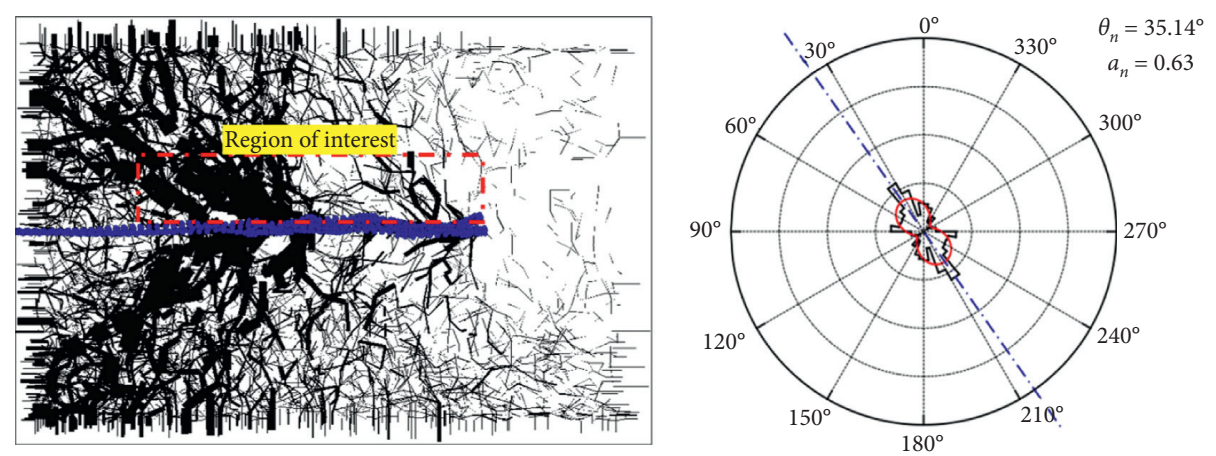

(b)
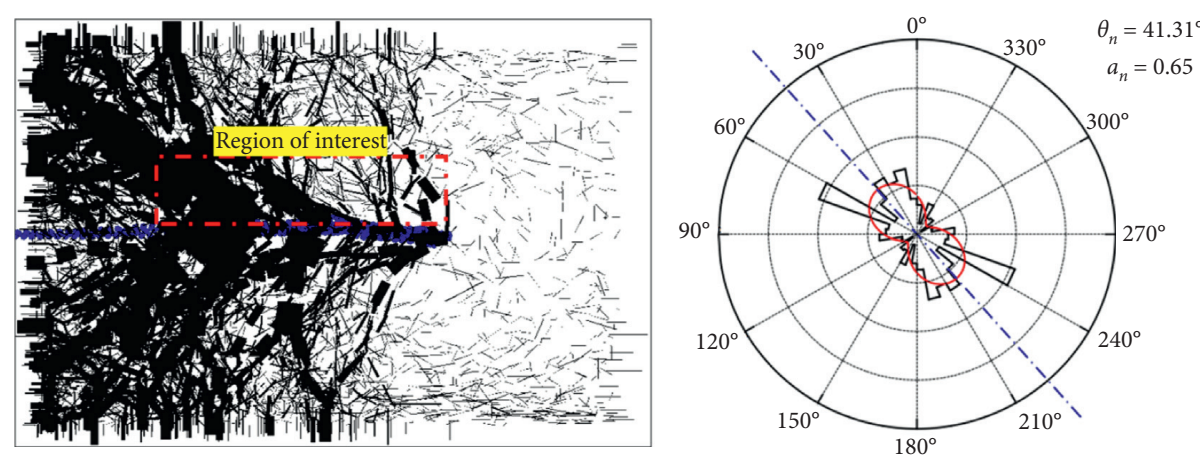

(c)

Figure 7: Continued. 

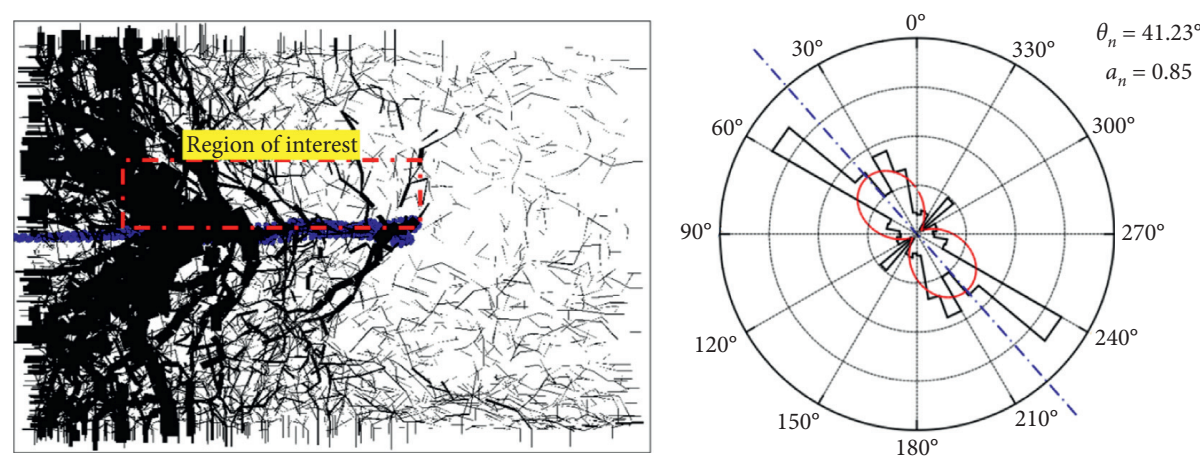

(d)

Figure 7: Evolution and anisotropy of normal contact force in the region of interest. (a) $\delta=9 \mathrm{~mm}$. (b) $\delta=36 \mathrm{~mm}$. (c) $\delta=63 \mathrm{~mm}$. (d) $\delta=81 \mathrm{~mm}$.

Figure 7) is presented under different pullout displacements. The solid line and the dashed line represent the actual results of numerical simulation and the principal directions of anisotropy after Fourier series approximation, respectively. It can be seen that, in the left row of Figure 7(a), the contact normal force is vertically distributed across the particle assembly, and the principal direction of contact normal force is approximately $19.87^{\circ}$. It is observed from Figures $7(\mathrm{~b})$ and 7 (c) that, with the development of pullout tests, the principal direction of contact normal force gradually deflects towards the horizontal direction, and the inclined angle between the principal direction of contact normal force and the vertical direction increases from $35.14^{\circ}$ to $41.31^{\circ}$. The area enclosed by the solid line gradually increases, indicating that the contact normal force is strengthened. The final state is shown in Figure 7(d), and the principal direction of contact normal force $\theta_{n}$ is almost unchanged. The results shown above are conducive to understand the transfer and distribution mechanism of contact force between particles. On the whole, the proposed Fourier approximation method can express the mechanical transfer mechanism of geogrid reinforced ballast well, and the evolution of force chain is consistent with the results reported by Dyer [33].

3.5. Correlation between Macroindices and Microindices. The interfacial strength of the specimen is not merely determined by the anisotropic coefficients of contact normal force $a_{n}$, but the average value of contact normal force $f_{0}$ and the principal directions of contact normal force $\theta_{n}$ possibly play significant roles in macroscopic strength. To clarify the dominating factors that govern the development of the macroscopic strength, the pullout force that corresponds to the interface strength and three fitting indexes mentioned above is normalized; hence, the inherent connections among normalized pullout force $f$, normalized $a_{n}$, normalized $\theta_{n}$ and normalized $f_{0}$ can be intuitively described, as depicted in Figure 8. It can be demonstrated that the development of normalized $f$, normalized $f_{0}$ and normalized $\theta_{n}$ is generally consistent before the peak $\theta_{n}$ arises; thereafter, maximum $f$ and maximum $f_{0}$ appear at the end of pullout test. The statistical results indicate that a large mobilization of ballast assembly is renewably distributed as the pullout test develops. However, compared with the other indexes, the development of normalized $a_{n}$ is completely different. Moreover, the correlation coefficients between normalized $f$ and normalized $\theta_{n}$, normalized $f_{0}$ are 0.88 and 0.87 , respectively, so the macroscopic strength of geogrid reinforced ballast can be better reflected by normalized $\theta_{n}$, indicating that the principal direction of contact normal force rotates more synchronously with the evolution of pullout force.

\section{Influence of Particle Orientation: Macroperformance and Micromechanism}

Particles assembly with optimum initial orientation is expected to play a significant role in the working performance of geogrid reinforced ballast. Besides the specimen with $45^{\circ}$ orientation mentioned above, other five specimens with $0^{\circ}$, $30^{\circ}, 60^{\circ}, 90^{\circ}$, and random orientation were selected to discuss the influence of ballast particles with different initial orientations.

4.1. Evolution of Pullout Force. To gain insight into the orientation effect of the six specimens with $0^{\circ}, 30^{\circ}, 45^{\circ}, 60^{\circ}$, $90^{\circ}$, and random one, the pullout force of geogrid embedded in ballast assembly is particularly given under low normal stresses of $20 \mathrm{kPa}$. As shown in Figure 9, the pullout forces for all specimens show a similar trend until the first $30 \mathrm{~mm}$ of pullout displacement (as distinguished in section A). Thereafter, the pullout force shows a different incremental rate around 30 to $90 \mathrm{~mm}$ of pullout displacement (as distinguished in section B). It can be seen from section $B$ that the pullout forces of specimens with $0^{\circ}, 60^{\circ}$, and random orientation shows a sharp drop after the peak pullout force, and the specimens with $30^{\circ}$ and $90^{\circ}$ orientation fluctuate slightly. However, the specimen with $45^{\circ}$ orientation shows peak value at the end of the test, indicating that a continuous increment of pullout force can be obtained during the whole test process, and the strength of a geogrid-reinforced system is gradually enhanced. The results shown in Figure 9 reflect the effect of particle orientation on the macro-strength of the 


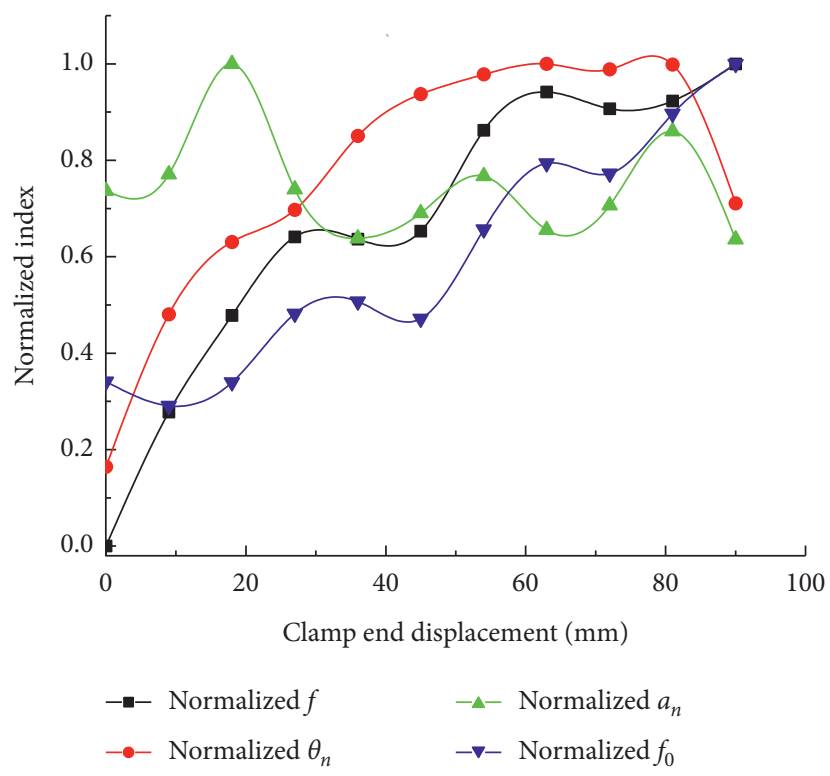

FIGURE 8: Comparison amongst the variation curves of normalized $f$ : normalized $\theta_{n}$, normalized $f_{0}$, and normalized $a_{n}$.

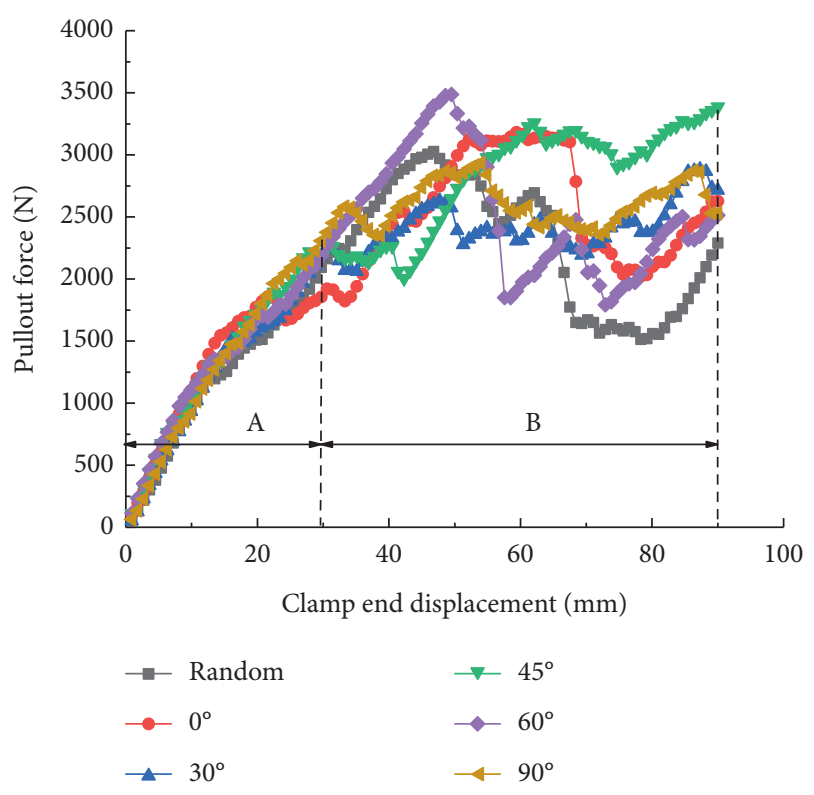

FIGURE 9: Variation of pullout force versus clamp end displacement.

geogrid-ballast interface, and sufficient relative displacement between geogrid and ballast is allowed for specimen with $45^{\circ}$ initial orientation, which is promising to improve the ductility of the geogrid reinforced ballast.

4.2. Influence of Particle Orientation on the Principal Directions of Contact Normal Force. Figure 10 shows the evolution of particles orientation for different pullout displacements. It can be seen from Table 2 that the orientations of specimens with $0^{\circ}, 30^{\circ}, 45^{\circ}$ orientation increase to $54.06^{\circ}, 55.15^{\circ}$, and $56.41^{\circ}$, but the specimens with $60^{\circ}$ and $90^{\circ}$ orientation decrease to $57.51^{\circ}$ and $58.73^{\circ}$, respectively. Thus, the characteristics of the particle angle are weakened during model preparation; this is because large mobilization of ballast assembly was caused after applying the gravitational field and specified normal stress. According to the variance analysis, there is no significant variation in actual orientation for five specific specimens. And in Figure 10 (the shaded area), especially the optimum interval from $56.68^{\circ}$ to $57.30^{\circ}$ is obtained, which benefits the maintenance of the interface strength during the whole pullout test. Therefore, all specimens possibly possess self-adapting character to resist the disturbance imported from the clamp end.

The pullout forces difference for different specimens has been analyzed in the preceding subsection, and the macroscopic response of ballast assembly is determined by the mesoscopic fabric evolution. Based on a much higher correlation coefficient between pullout force and principal direction of contact normal force, the evolution of $\theta_{n}$ is selected to discuss the fabric responses of ballast assembly with diverse initial orientation. As shown in Figure 11, the values of the principal directions of contact normal force for different specimens are pretty small at the beginning and then increase with the development of pullout test. Especially, the specimens with $0^{\circ}, 30^{\circ}, 60^{\circ}, 90^{\circ}$, and random orientation show uneven development, but the specimen with $45^{\circ}$ orientation increases uniformly during the process of pullout test. This phenomenon proves the supposition that the specimen with $45^{\circ}$ orientation can keep the ballast assembly in more stable state. Accordingly, based on the analysis of the principal directions of contact normal force 


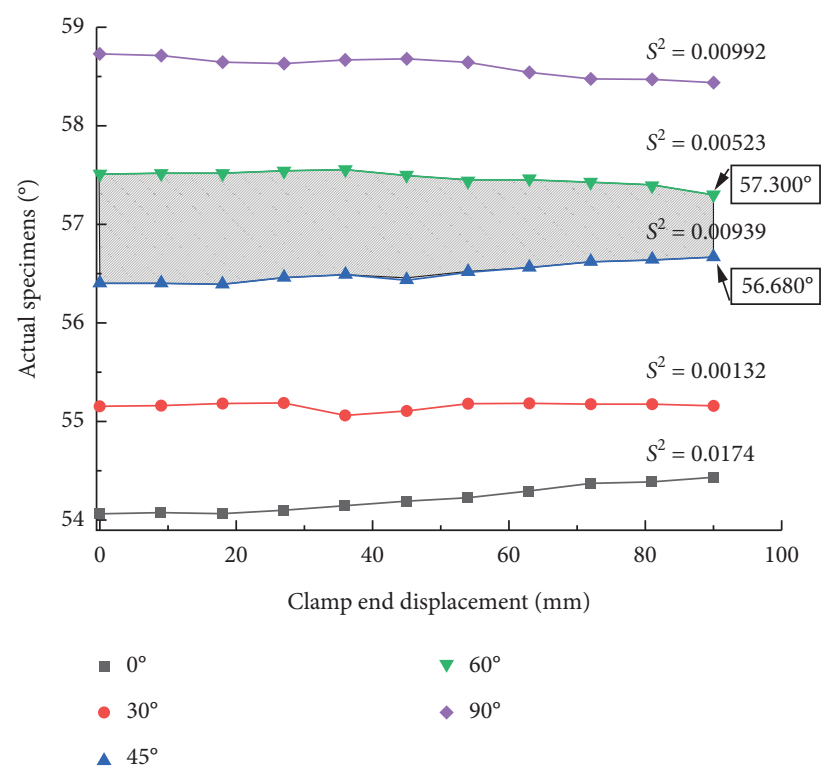

Figure 10: Angle variation for different angle specimens.

TABLE 2: Orientations variation.

\begin{tabular}{|c|c|c|c|c|c|}
\hline Initial orientations of different specimens & $0.00^{\circ}$ & $30.00^{\circ}$ & $45.00^{\circ}$ & $60.00^{\circ}$ & $90.00^{\circ}$ \\
\hline Actual orientations before the introduction of pullout load & $54.06^{\circ}$ & $55.15^{\circ}$ & $56.41^{\circ}$ & $57.51^{\circ}$ & $58.73^{\circ}$ \\
\hline
\end{tabular}

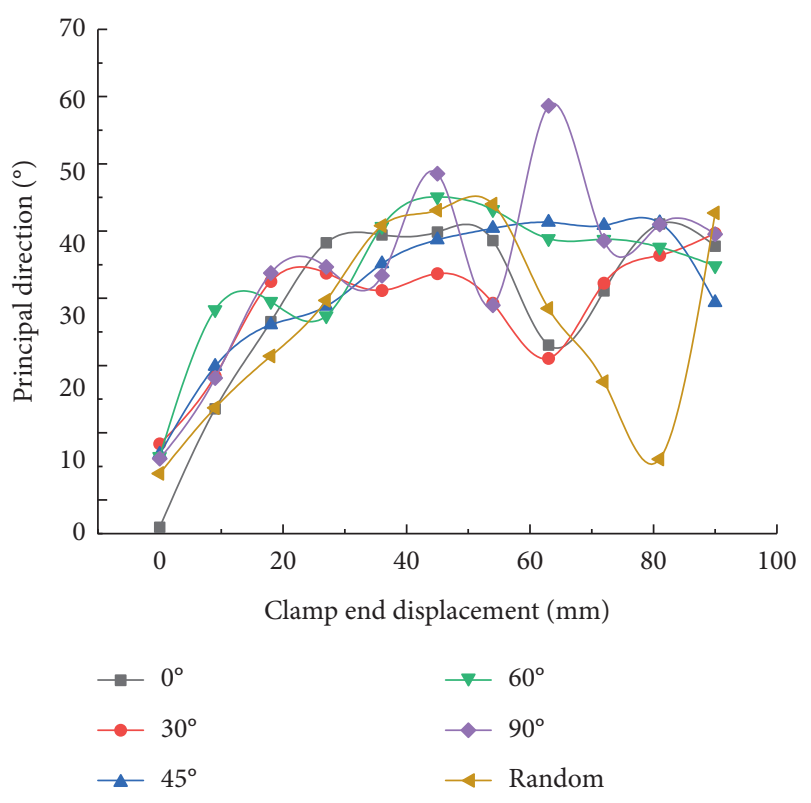

Figure 11: Principal directions versus different clamp end displacements.

for the five ballast specimens, the spatial orientation of ballast assembly should be paid more attention in the perspective of reinforcement effect in practice.

\section{Conclusion}

In this article, a numerical model using PFC3D is established to reproduce the pullout behavior of the triaxial geogrid embedded in ballast aggregates, and the influence of the initial orientation of ballast assembly with the angles of $0^{\circ}$, $30^{\circ}, 45^{\circ}, 60^{\circ}, 90^{\circ}$ and random orientation on the geogridballast interface strength are explored from the macro and micro-perspectives. So, the optimal particle assembly is justified, and the main conclusions are drawn:

(a) The mechanical response of the geogrid embedded in ballast with $45^{\circ}$ orientation is qualitatively explored; a much higher correlation coefficient between normalized pullout force $f$ and normalized principal directions of contact normal force $\theta_{n}$ is discovered.

(b) The comprehensive analysis compares the development of pullout force amongst the specimens with $0^{\circ}$, $30^{\circ}, 45^{\circ}, 60^{\circ}, 90^{\circ}$, and random orientation during the pullout test, and a more stable development of interface strength and better ductility is observed for ballast assembly with $45^{\circ}$ initial orientation.

(c) The stability of the $45^{\circ}$ specimen is justified from perspectives of the mesoscopic fabric and the principal directions of contact normal force, indicating that the specimen with $45^{\circ}$ initial orientation shows better systematic stability, and a relatively 
stable interval of $56.68^{\circ}$ to $57.30^{\circ}$ is observed to better resisting the disturbance of the pullout load for ballast assembly.

\section{Data Availability}

The authors would provide the data once the manuscript is accepted.

\section{Conflicts of Interest}

The authors declare no conflicts of interest.

\section{Authors' Contributions}

Conceptualization was performed by Jian-bin Zhao and Chen-xi Miao; methodology was proposed by Jian-bin Zhao and Xiao-hong Bai; software was provided by Jian-bin Zhao and Chen-xi Miao; formal analysis was performed by Jie Li; original draft was prepared by Jie $\mathrm{Li}$; review and editing were carried out by Jie Li and Chen-xi Miao; supervision was conducted by Chen-xi Miao and Jun Zhang; funding acquisition was performed by Chen-xi Miao and Xiao-hong Bai. All authors have read and agreed to the published version of the manuscript.

\section{Acknowledgments}

The authors thank the National Natural Science Foundation of China (No. 51809191), China Postdoctoral Science Foundation funded project (No. 2019M661065), Key Research and Development Projects of Shanxi Province (No. 201803D31047), and Science and Technology Project of Shanxi Transportation Holdings Group Co., Ltd. (No. 20JKKJ-11) for funding this work.

\section{References}

[1] S. Alamshahi and N. Hataf, "Bearing capacity of strip footings on sand slopes reinforced with geogrid and grid-anchor," Geotextiles and Geomembranes, vol. 27, no. 3, pp. 217-226, 2009.

[2] J. Han and M. A. Gabr, "Numerical analysis of geosyntheticreinforced and pile-supported earth platforms over soft soil," Journal of Geotechnical and Geoenvironmental Engineering, vol. 128, no. 1, pp. 44-53, 2002.

[3] M. Y. Abu-Farsakh, I. Almohd, and K. Farrag, "Comparison of field and laboratory pullout tests on geosynthetics in marginal soils," Transportation Research Record: Journal of the Transportation Research Board, vol. 1975, no. 1, pp. 124-136, 2006.

[4] Z. Wang, F. Jacobs, M. Ziegler, and G. Yang, "Visualisation and quantification of geogrid reinforcing effects under strip footing loads using discrete element method," Geotextiles and Geomembranes, vol. 48, no. 1, pp. 62-70, 2020.

[5] B. Sierra and S. Viviana, "DEM analysis of rock bridges and the contribution to rock slope stability in the case of translational sliding failures," International Journal of Rock Mechanics and Mining Sciences, vol. 80, pp. 67-78, 2015.

[6] G. R. Mcdowell, O. Harireche, H. Konietzky, S. F. Brown, and N. H. Thom, "Discrete element modelling of geogrid-reinforced aggregates," Proceedings of the Institution of Civil
Engineers-Geotechnical Engineering, vol. 159, no. 1, pp. 35-48, 2006.

[7] A. M. N. Alagiyawanna, M. Sugimoto, S. Sato, and H. Toyota, "Influence of longitudinal and transverse members on geogrid pullout behavior during deformation," Geotextiles and Geomembranes, vol. 19, no. 8, pp. 483-507, 2001.

[8] C. Yan-Jun, L. Yong, and X. Heng-Lin, "Experimental investigations on the pullout behavior of tire strips reinforced sands," Materials, vol. 10, no. 7, p. 707, 2017.

[9] N. Moraci and P. Recalcati, "Factors affecting the pullout behaviour of extruded geogrids embedded in a compacted granular soil," Geotextiles and Geomembranes, vol. 24, no. 4, pp. 220-242, 2006.

[10] F. M. Ezzein and R. J. Bathurst, “A new approach to evaluate soil-geosynthetic interaction using a novel pullout test apparatus and transparent granular soil," Geotextiles and Geomembranes, vol. 42, no. 3, pp. 246-255, 2014.

[11] S. H. C. Teixeira, B. S. Bueno, and J. G. Zornberg, "Pullout resistance of individual longitudinal and transverse geogrid ribs," Journal of Geotechnical and Geoenvironmental Engineering, vol. 133, no. 1, pp. 37-50, 2007.

[12] E. M. Palmeira, "Soil-geosynthetic interaction: modelling and analysis," Geotextiles and Geomembranes, vol. 27, no. 5, pp. 368-390, 2009.

[13] K. Farrag, Y. B. Acar, and I. Juran, "Pull-out resistance of geogrid reinforcements," Geotextiles and Geomembranes, vol. 12, no. 2, pp. 133-159, 1993.

[14] K. Cafer and A. Gökhan, "Experimental study on pullout response of geogrid embedded in sand," Journals \& Books, vol. 117, pp. 390-396, 2008.

[15] M. Sugimoto, A. M. N. Alagiyawanna, and K. Kadoguchi, "Influence of rigid and flexible face on geogrid pullout tests," Geotextiles and Geomembranes, vol. 19, no. 5, pp. 257-277, 2001.

[16] M. G. Hussein and M. A. Meguid, "A three-dimensional finite element approach for modeling biaxial geogrid with application to geogrid-reinforced soils," Geotextiles and Geomembranes, vol. 44, no. 3, pp. 295-307, 2016.

[17] M. Y. Fattah and Q. G. Majeed, "Finite element analysis of geogrid encased stone columns," Geotechnical and Geological Engineering, vol. 30, no. 4, pp. 713-726, 2012.

[18] S. Yijie, X. Hongzhong, G. Peng et al., "Application of FBG sensing technology in stability analysis of geogrid-reinforced slope," Sensors, vol. 17, no. 3, p. 597, 2017.

[19] H. Huang and S. Chrismer, "Discrete element modeling of ballast settlement under trains moving at "Critical Speeds"” Construction and Building Materials, vol. 38, pp. 994-1000, 2013.

[20] B. Suhr, S. Marschnig, and K. Six, "Comparison of two different types of railway ballast in compression and direct shear tests: experimental results and DEM model validation," Ganular Matter, vol. 20, no. 4, 2018.

[21] G. C. Vizcarra, S. Nimbalkar, M. Casagrande, and M. Casagrande, "Modeling behaviour of railway ballast in prismoidal apparatus using discrete element method," Procedia Engineering, vol. 143, pp. 1177-1184, 2016.

[22] L. Rothenburg and R. J. Bathurst, "Analytical study of induced anisotropy in idealized granular materials," Géotechnique, vol. 39, no. 4, pp. 601-614, 1989.

[23] M. Jiang, T. Li, and Z. Shen, "Fabric rates of elliptical particle assembly in monotonic and cyclic simple shear tests: a numerical study," Granular Matter, vol. 18, no. 3, p. 54, 2016.

[24] D. Barreto and C. O'Sullivan, "The influence of inter-particle friction and the intermediate stress ratio on soil response 
under generalised stress conditions," Granular Matter, vol. 14, no. 4 , pp. 505-521, 2012.

[25] J. M. Ting and B. T. Corkum, "Strength behavior of granular materials using discrete numerical modeling," Numerical Methods in Geomechanics, vol. 14, pp. 305-310, 1988.

[26] M. M. Biabani, N. T. Ngo, and B. Indraratna, "Performance evaluation of railway subballast stabilised with geocell based on pull-out testing," Geotextiles and Geomembranes, vol. 44, no. 4, pp. 579-591, 2016.

[27] C.-X. Miao, J.-J. Zheng, R.-J. Zhang, and L. Cui, "DEM modeling of pullout behavior of geogrid reinforced ballast: the effect of particle shape," Computers and Geotechnics, vol. 81, pp. 249-261, 2017.

[28] N. T. Ngo, B. Indraratna, and C. Rujikiatkamjorn, "DEM simulation of the behaviour of geogrid stabilised ballast fouled with coal," Computers and Geotechnics, vol. 55, no. 1, pp. 224-231, 2014.

[29] V. D. H. Tran, M. A. Meguid, and L. E. Chouinard, "A finitediscrete element framework for the 3D modeling of geogridsoil interaction under pullout loading conditions," Geotextiles and Geomembranes, vol. 37, pp. 1-9, 2013.

[30] M. Stahl, H. Konietzky, L. Te Kamp, and H. Jas, "Discrete element simulation of geogrid-stabilised soil," Acta Geotechnica, vol. 9, no. 6, pp. 1073-1084, 2014.

[31] M. Sugimoto and A. M. N. Alagiyawanna, "Pullout behavior of geogrid by test and numerical analysis," Journal of Geotechnical and Geoenvironmental Engineering, vol. 129, no. 4, pp. 361-371, 2003.

[32] C. Suksiripattanapong, S. Horpibulsuk, A. Chinkulkijniwat, and J. C. Chai, "Pullout resistance of bearing reinforcement embedded in coarse-grained soils," Geotextiles and Geomembranes, vol. 36, pp. 44-54, 2013.

[33] M. R. Dyer and G. W. E. Milligan, Observation of the Stress Distribution in Crushed Glass with Applications to Soil reinforcement, University of Oxford, London, UK, 1985. 